\title{
Improved Efficiency and Throttling Range of the VX-200 Magnetoplasma Thruster
}

\author{
Benjamin W. Longmier* \\ University of Michigan, Ann Arbor, Michigan 48108 \\ Jared P. Squire \pm and Chris S. Olsen \pm \\ Ad Astra Rocket Company, Webster, Texas 77598 \\ Leonard D. Cassady $\underline{\underline{s}}$ \\ Jacobs Engineering, Houston, Texas 77058 \\ Maxwell G. Ballenger $\mathbb{I}$ \\ Space Exploration Technologies, McGregor, Texas 76657 \\ Mark D. Carter, $\stackrel{\text { ** }}{-}$ Andrew V. Ilin,辛 and Tim W. Glover莘 \\ Ad Astra Rocket Company, Webster, Texas 77598 \\ Greg E. McCaskill $\underline{\S \S}$ \\ Ion Geophysical, Stafford, Texas 77477 \\ Franklin R. Chang DíazII \\ Ad Astra Rocket Company, Webster, Texas 77598 \\ and \\ Edgar A. Bering, III**** \\ University of Houston, Houston, Texas 77004 \\ DOI: $\underline{10.2514 / 1 . B 34801}$
}

\begin{abstract}
Testing of the Variable Specific Impulse Magnetoplasma Rocket VX-200 engine was performed over a wide throttle range in a $150 \mathrm{~m}^{3}$ vacuum chamber with sufficient pumping to permit exhaust plume measurements at argon background pressures less than $1 \times 10^{-3} \mathrm{~Pa}\left(1 \times 10^{-5}\right.$ torr $)$ during firings, ensuring charge-exchange mean free paths longer than the vacuum chamber. Measurements of plasma flux, radio frequency power, propellant flow rate, and ion kinetic energy were used to determine the ionization cost of argon and krypton in the helicon discharge. Experimental data on ionization cost, ion fraction, exhaust plume expansion angle, thruster efficiency, and thrust are presented that characterize the VX-200 engine performance over a throttling range from 15 to $200 \mathrm{~kW}$ radio frequency power. A semiempirical model of the thruster efficiency as a function of specific impulse indicates an ion cyclotron heating efficiency of $85 \pm 7 \%$. Operation at a total radio frequency coupled power level of $200 \mathrm{~kW}$ yields a thruster efficiency of $72 \pm 6 \%$ at a specific impulse of $4900 \pm 300 \mathrm{~s}$ with argon propellant. A high thrust-to-power operating mode was characterized over a wide parameter space with a maximum thrust-to-power ratio of $51 \pm$ $5 \mathrm{mN} / \mathrm{k} \mathrm{W}$ at a specific impulse of $1660 \pm 100 \mathrm{~s}$ for a ratio of ion cyclotron heating radio frequency power to helicon radio frequency power of $0.7: 1$.
\end{abstract}

\section{Nomenclature}

$\begin{array}{ll}e & = \\ E_{i} & = \\ E_{1} & = \\ E_{\|}, E_{\perp} & =\end{array}$

electron charge, $\mathrm{C}$

ionization cost, $\mathrm{eV}$

ion kinetic energy after helicon, eV

ion kinetic energy, eV
Presented as Paper 2012-3930 at the 48th AIAA/ASME/SAE/ASEE Joint Propulsion Conference, Atlanta, GA, 29 July-1 August 2012; received 25 September 2012; revision received 16 April 2013; accepted for publication 17 April 2013; published online 31 December 2013. Copyright (C) 2013 by the American Institute of Aeronautics and Astronautics, Inc. All rights reserved. Copies of this paper may be made for personal or internal use, on condition that the copier pay the $\$ 10.00$ per-copy fee to the Copyright Clearance Center, Inc., 222 Rosewood Drive, Danvers, MA 01923; include the code 1533-3876/ 13 and $\$ 10.00$ in correspondence with the CCC.

*Assistant Professor, Department of Aerospace Engineering; Longmier@ umich.edu.

†Director of Research; jared.squire@ adastrarocket.com.

‡Senior Research Scientist; chris.olsen@ adastrarocket.com.

${ }^{\S}$ Research Engineer; leonard.d.cassady@ nasa.gov.

"Software Engineer; ballengerm@gmail.com.

**Director of Technology; mark.carter@adastrarocket.com.

${ }^{\dagger}$ Computational Research Lead; andrew.ilin@adastrarocket.com.

*Director of Development; tim.glover@ adastrarocket.com.

\$Staff Electrical Engineer; Greg.McCaskill@iongeo.com.

"TChief Executive Officer; aarcinfo@ adastrarocket.com.

***Professor, Physics and ECE; eabering@uh.edu.

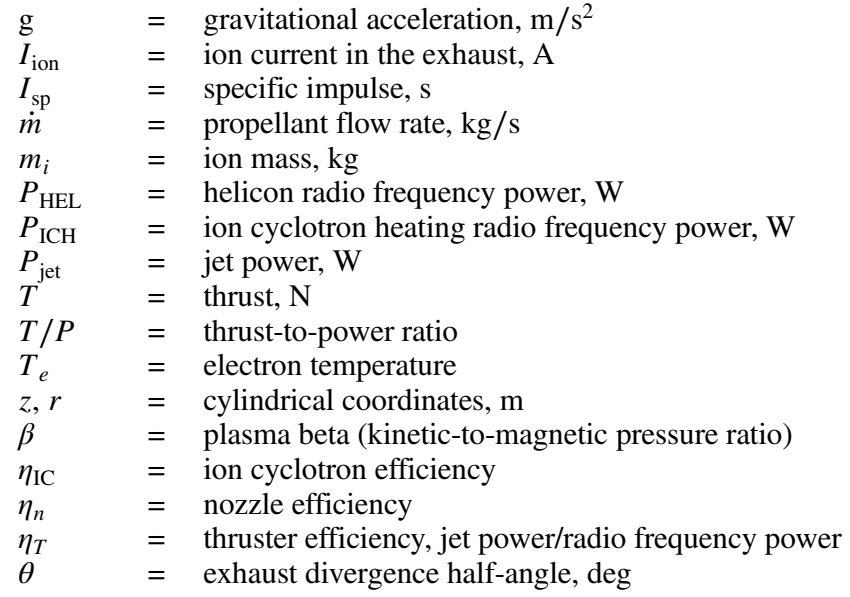

\section{Introduction}

$\mathbf{H}$ IGH-POWER electric propulsion thrusters can reduce propellant mass for heavy-payload orbit-raising missions and cargo missions to the moon and near-Earth asteroids and can reduce the trip time of robotic and piloted planetary missions [1-4]. The Variable Specific Impulse Magnetoplasma Rocket (VASIM̄ $\overline{\text { ) }}$ VX200 engine is an electric propulsion system capable of processing 
power densities on the order of $6 \mathrm{MW} / \mathrm{m}^{2}$ at the exit area with a high specific impulse (2000 to $5000 \mathrm{~s}$ ) and an inherent capability to vary the thrust and specific impulse at a constant input power.

The potential for increased thruster lifetime is due primarily to the radial magnetic confinement of both ions and electrons in a quasineutral flowing plasma stream, which acts to significantly reduce the plasma impingement on the surfaces of the engine core. Hightemperature ceramic plasma-facing surfaces handle the thermal radiation: the principal heat transfer mechanism from the discharge. The engine uses a helicon plasma source [5,6] for efficient plasma production in the first stage. This plasma is energized further by an ion cyclotron heating $(\mathrm{ICH})$ radio frequency $(\mathrm{RF})$ stage that uses lefthand polarized slow mode waves launched from the high field side of the ion cyclotron resonance. Useful thrust is produced as the plasma accelerates in an expanding magnetic field, a process described by conservation of the first adiabatic invariant as the magnetic field strength decreases in the exhaust region of the VASIMR [7-10]. Conservation of each plasma particle's magnetic moment depends upon the scale length of the magnetic field and the cyclotron radius $[\underline{8}, \underline{11}]$. Any experiment to adequately measure and quantify the detachment process in a magnetic nozzle would require a system large enough 1) for the conversion process to occur, 2) for sufficient unimpeded volume for the plume to expand during detachment, and 3 ) in a low enough vacuum environment where particle sources/ losses are minimized (i.e., charge-exchange and impact ionization mean free paths are minimized) [12-17]. For high-density magnetized flow, as in the VX-200 engine (a $200 \mathrm{~kW}$ VASIMR laboratory prototype), this axial distance can range from approximately 50 to $300 \mathrm{~cm}[12,17-19]$. Measurement of the nozzle plume over magnetic field strengths spanning several orders of magnitude is desirable, which for nonexotic topologies (i.e., dipole) may extend into the region several meters [12,14]. Recent experiments in the VX-200, satisfying the aforementioned conditions, have indicated that plasma detachment is occurring within a few meters downstream of the magnetic nozzle throat [12].

\section{Experimental Setup and Method}

\section{A. VX-200 Engine}

The VX-200 engine is an experimental VASIMR prototype designed to operate at $200 \mathrm{~kW}$ of input dc electrical power. The device provides an end-to-end integrated test of the primary VASIMR components in a vacuum environment with the goal of measuring and improving the system performance. A majority of the VX-200 engine components are located within the vacuum chamber, with only the solid-state RF generators, superconducting magnet power supplies, and cryocoolers kept at atmospheric pressure.

The superconducting magnet, support structure, engine core, engine sensors, and electrical components are operated within the vacuum chamber. Figure 1 shows a schematic of the VX-200 engine installed inside the vacuum chamber and the shape of the magnetic field flux lines within the core and magnetic nozzle. All other magnetic field lines within the magnetic nozzle fall within the confines of the field lines drawn in Fig. 1.

The core of the VX-200 engine is defined as the components that physically surround the plasma and intercept the bulk of the waste heat radiated by the plasma column. The VX-200 engine is restricted to pulses of less than $1 \mathrm{~min}$, owing to temperature limitations of organic seals and joints in the engine core. The commanded and measured RF power, thrust, and flow rate are all steady to within $1 \%$ from $500 \mathrm{~ms}$ out to the end of the $60 \mathrm{~s}$ pulse, ensuring a steady-state operating condition. The helicon stage launches a right-handed circularly polarized wave to produce a cold plasma, with an average electron temperature between 2 and $10 \mathrm{eV}$, depending on the RF power and propellant flow rate. A pressure gradient drives the plasma flow through a magnetic choke into the ion cyclotron heating stage where another RF coupler launches a wave that preferentially heats the ions in a single pass [9]. All plasma-facing engine components are electrically floating, as is the partition, except for a small area of metal support structure. The vacuum chamber is grounded with ground stakes.

The VX-200 engine RF generators convert facility dc power to RF power and perform impedance matching between the RF generator output and the engine core (Fig. 2). The solid-state RF generators were custom built by Nautel, Ltd., model numbers VX200-1 (helicon generator) and VX200-2 (ICH generator). The VX200-1 RF generator is rated up to $48 \pm 1 \mathrm{~kW}$ RF with a $91 \pm 1 \%$ efficiency, a specific mass of $0.85 \pm 0.02 \mathrm{~kg} / \mathrm{kW}$, and at a frequency near the industrial standard of $6.78 \mathrm{MHz}$. The VX200-2 generator is rated up to $172 \pm 1 \mathrm{~kW} \mathrm{RF}$ with a $98 \pm 1 \%$ efficiency, a specific mass of $0.506 \pm 0.003 \mathrm{~kg} / \mathrm{kW}$, and at a frequency of several hundred kilohertz. The generator efficiencies were determined by independent testing performed by Nautel, Ltd., which included a direct measurement of input power and calorimetry of the dissipated power in the generator.

The RF impedance matching systems for both stages are custom built with commonly used $\mathrm{L}$ networks of capacitors $[\underline{9}, \underline{20}]$ installed in

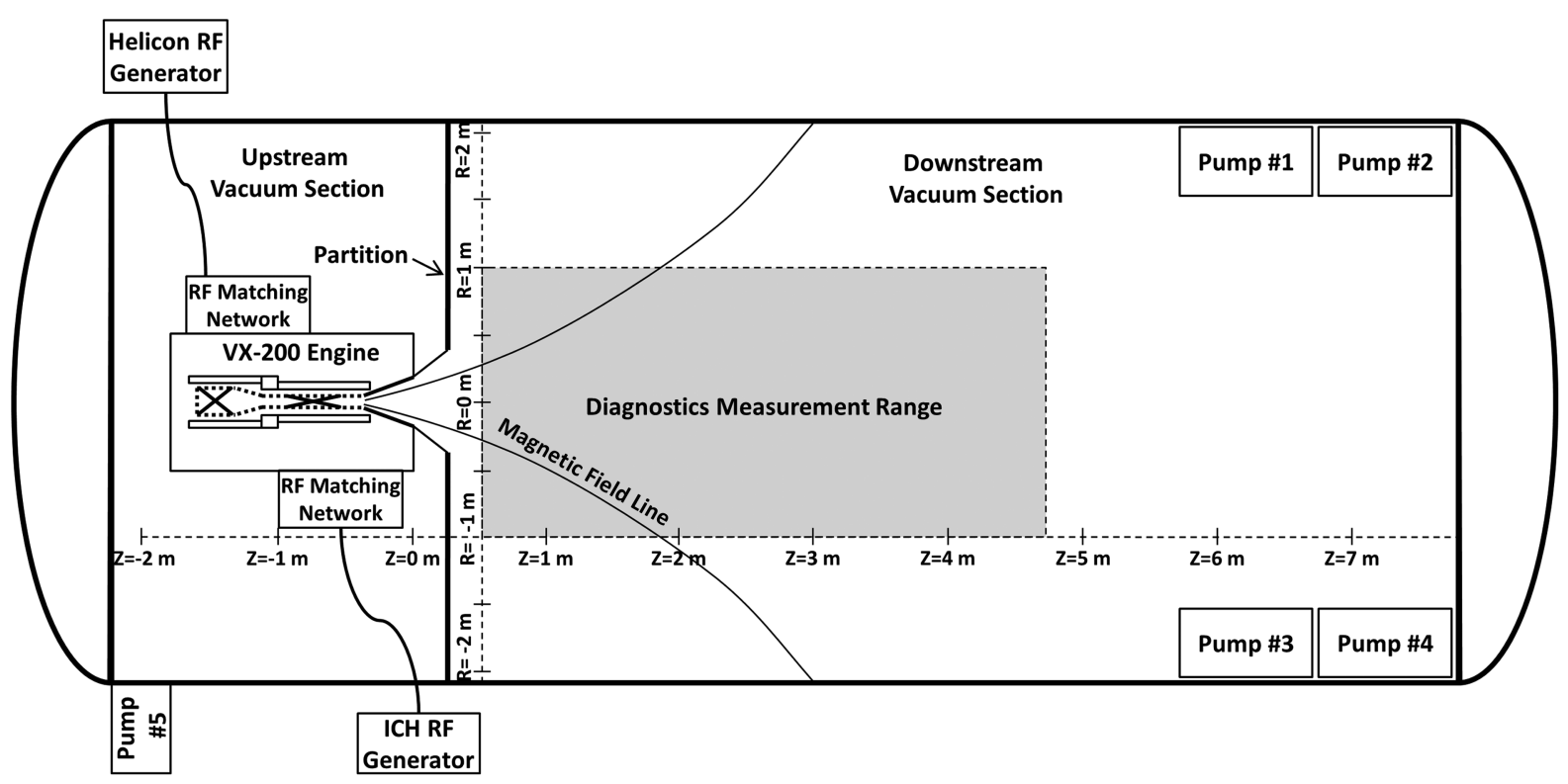

Fig. 1 Schematic of the $10 \mathrm{~m}$ long $\times 4.2 \mathrm{~m}$ diameter vacuum chamber and the VX-200 engine, $\mathrm{RF}$ generators, RF power measurement location, vacuum partition, representative magnetic field lines, and the measurement range of the exhaust plume diagnostics. Shaded region in the plume is the region mapped out by the diagnostics suite. 


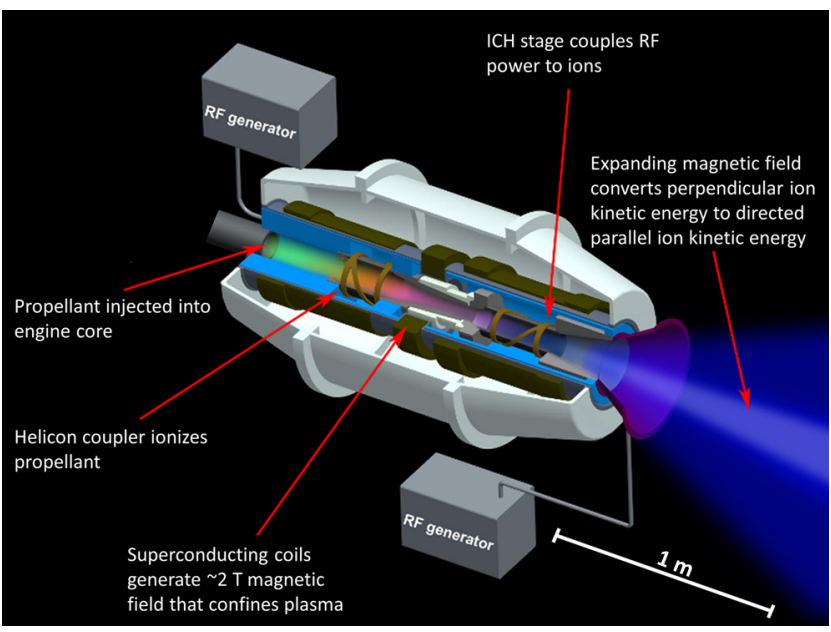

Fig. 2 Conceptual schematic of the VASIMR engine.

the vacuum chamber within $0.5 \mathrm{~m}$ the $\mathrm{RF}$ couplers. A variable capacitance "tune" capacitor is in parallel with the RF coupler and grounded at one end. Another variable capacitance capacitor, a series "load" capacitor, connects to a $3 \mathrm{~m}$ transmission line leading to the RF generator. This L-network matching network uses low-loss $10-\mathrm{kV}$ rated ceramic and vacuum-variable-type capacitors. The RF matching networks are installed in aluminum enclosures that are electrically bonded to the structure of VX-200 engine. High-power $\mathrm{RF}$ vacuum feedthroughs are used to pass the transmission lines through the vacuum chamber and custom-designed coaxial lines that are grounded to the chamber. RF power is measured by calibrated phase sensitive voltage and current sensors in the RF generators.

The exhaust velocity of the ions increases as the coupled ICH power increases. Coupled RF power is defined as the RF power that is injected by the helicon and/or ICH couplers and is inductively absorbed by the plasma column and/or radiatively lost by the RF couplers. The coupled RF power is determined by subtracting the power losses in the RF matching network and RF transmission line from the measured RF power at the RF generator output (Fig. 1). Losses in the matching networks and transmissions lines are calculated based on network analyzer measurements of circuit impedance. The efficiency was determined to be $96 \%$ for both the helicon and ICH RF circuits.

The VX-200 engine low-temperature superconducting magnet is cooled to $6 \mathrm{~K}$ by a pair of Sumitomo cryocooler (RDK-408D2)/ cryocompressor (CSW-71) units with a maximum combined power draw of $15 \mathrm{~kW}$. The VX-200 engine magnet produces a maximum magnetic field strength of $20,000 \mathrm{G}$ that results in highly confined electrons and ions within the engine core. The ion gyroradius under nominal operating conditions before the ICH stage is less than $1 \mathrm{~mm}$. Estimates for cryocooler power draw for flight designs are less than $3 \mathrm{~kW}$ total for high-temperature superconducting magnets cooled to $50 \mathrm{~K}$. The magnetic field in the VX-200 engine is responsible for efficient ion cyclotron coupling of the RF energy to the ions within the quasi-neutral flowing plasma. The applied expanding magnetic field converts perpendicular ion kinetic energy $E_{\perp}$ to directed parallel ion kinetic energy $E_{\|}$through conservation of the magnetic moment and conservation of the ion's total kinetic energy [7-9]. The on-axis location by which $90 \%$ of the perpendicular ion energy has been converted into parallel ion energy, $E_{\|} /\left(E_{\|}+E_{\perp}\right)=0.9$, occurs at $Z=0.05 \mathrm{~m}$.

An ambipolar ion acceleration has also been observed [16] and is believed to be the result of the plasma interaction with the magnetic field gradient in the expanding magnetic nozzle of the VX-200 engine, similar to the Boltzmann relation but with a varying electron temperature. The ambipolar ion acceleration typically results in an additional directed ion velocity of 5 to $10 \mathrm{~km} / \mathrm{s}$, where the energy for this process comes from the electron energy distribution function as a result of electron and ion interaction via a weak electric field in the magnetic nozzle, which ranges in strength from 10 to $20 \mathrm{~V} / \mathrm{m}$ depending on system parameters. The ambipolar measurements were taken $3 \mathrm{~m}$ downstream of the engine exit plane.

\section{B. Vacuum Facility}

The VX-200 engine is installed, as shown in Fig. 1, inside a stainless steel vacuum chamber $[10,17]$ that is $4.2 \mathrm{~m}$ in diameter and $10 \mathrm{~m}$ long with a volume of $150 \mathrm{~m}^{3}$ including the end caps. One end opens fully for access to the entire inner diameter of the chamber. The vacuum chamber is partitioned into two sections: an upstream section and a downstream section. The upstream vacuum section (where the VX-200 engine is located) is kept at a pressure one to two orders of magnitude lower than the downstream, or exhaust, vacuum section while the VX-200 is firing. The partition (with a hole in it), located at $Z=0.2 \mathrm{~m}$, helps to prevent arcing and glow discharges near the high-voltage transmission lines and matching circuit components of the VX-200. Similar work related to the challenges of operating a RF antenna in vacuum was performed by West et al. [18]. The magnetic field lines within the engine core of the rocket that have plasma initially attached to them do not intersect the partition. These magnetic field lines that initially carry the plasma stream do eventually intersect the downstream vacuum chamber surface, though at a strength ranging from 0.05 to $2 \mathrm{G}$. Testing was performed with three CVI Torr Master internal cryopumps in the downstream section of the vacuum chamber that provided an Ar pumping speed of $\sim 160,000 \mathrm{l} / \mathrm{s}$. Due to the chamber volume, the exhaust section pressure was below $1 \times 10^{-3} \mathrm{~Pa}\left(1 \times 10^{-5}\right.$ torr $)$ for the time window between 0 and $1.0 \mathrm{~s}$ after gas injection and less than $1 \times 10^{-2} \mathrm{~Pa}$ $\left(1 \times 10^{-4}\right.$ torr $)$ from 1.0 to $30 \mathrm{~s}$ of operation.

The data presented in this paper were taken during the time window from 0.8 to $1.0 \mathrm{~s}$ after gas injection, resulting in an $\mathrm{Ar}$ ion-neutral charge-exchange mean free path of $\sim 10 \mathrm{~m}$. Ion-ion scattering and electron-neutral ionization mean free paths in the downstream portion of the chamber are both longer than the chargeexchange mean free path during this interval. By collecting data in this narrow time window, neutral pressure effects on the plasma exhaust plume were minimized. Three downstream Bayard Alperttype pressure gauges (located at $z=3.3,4.1$, and $9.1 \mathrm{~m}$ ) and an MKS residual gas analyzer (located at $z=4.5 \mathrm{~m}$ ) are used to measure the pressure during firings. The pressure gauges have a response time of less than $100 \mathrm{~ms}$. Firing lengths during most of the campaign and data presented in this paper were kept to $\sim 1.2 \mathrm{~s}$ so that heating to the internal components of the VX-200 could be minimized and a large number of firings could be achieved in a testing period. The VX-200 is not a steady-state thermal device and overheats within $\sim 60 \mathrm{~s}$ of operation, requiring several hours to cool back down.

The propellant mass flow rate of the VX-200 was varied from 50 to $160 \mathrm{mg} / \mathrm{s}$ for argon and from 100 to $250 \mathrm{mg} / \mathrm{s}$ for krypton. The flow rate was measured by a calibrated proportional flow control valve flow controller [MOOG, Inc., part number CA47856-001 PFCV $(51 \times 362)$, serial number 0002 , with a time response of less than $3 \mathrm{~ms}$ and an accuracy of $\pm 0.2 \%$ full-scale operations] in addition to a National Institute of Standards and Technology traceable calibrated thermal-based mass flow meter (MKS 179A, with an accuracy of $\pm 1 \%$ full scale) that was in line at the high-pressure end of the propellant feed system. The uncertainty in the flow rate in the data time window between 0.8 and $1.0 \mathrm{~s}$ was measured as $\pm 1.3 \%$ over the flow rate range from 50 to $160 \mathrm{mg} / \mathrm{s}$ for argon. Furthermore, thrust measurements remain constant to within $\pm 1 \%$ from 0.6 out to $60 \mathrm{~s}$ during a firing.

\section{Flux Probe Array}

The ion flux in the exhaust plume of the VX-200 was measured with an array of $100.64-\mathrm{cm}$-diam molybdenum planar probes of a top-hat design [19] that were biased into the ion saturation regime: $-20 \mathrm{~V}$ with respect to chamber ground. Full current-voltage traces were taken with a Langmuir probe with a guard ring of the same dimensions and analyzed to ensure that the ion flux probes were biased $3 T_{e}$ more negative than the floating potential. Ion flux measurements were taken both during quick startup shots, where the ambient neutral gas pressure was below $1 \times 10^{-3} \mathrm{~Pa}\left(1 \times 10^{-5}\right.$ torr $)$ 
for both $\mathrm{Ar}$ and $\mathrm{Kr}$ operations, and during translating radial profiles where the sustained neutral argon pressure within the vacuum chamber was below $1 \times 10^{-2} \mathrm{~Pa}\left(1 \times 10^{-4}\right.$ torr $)$ for both $\mathrm{Ar}$ and $\mathrm{Kr}$ operations. The flux probe arrays were located at $z=70 \mathrm{~cm}$ and scanned radially in both directions for most of the data presented in this paper.

\section{Plasma Momentum Flux Sensor}

A plasma momentum flux sensor (PMFS), described in detail elsewhere [20], was used to measure the force of the plasma ejected from the VX-200 engine. The PMFS consists of a 9-cm-diam electrically floating graphite target disk attached to a stiff $10-\mathrm{cm}-$ long insulating alumina rod. The stiff alumina rod connects to a small titanium bar, 5.72 by $1.30 \mathrm{~cm}$, where a series of four high-output semiconductor strain gauges measure the strain caused by the torque from the applied plasma impact. The PMFS is calibrated with the method employed by Chavers and Chang-Diaz [21] and Chavers et al. [22]. A small graphite shield protects the entire titanium bar and strain gauge assembly from the flowing plasma stream.

The resolution of the PMFS is $0.1 \mathrm{mN}$, which is sufficient for precise measurement of the force applied by the exhaust plasma. Its natural frequency of oscillation is $40 \mathrm{~Hz}$; this oscillation is filtered out during the analysis of radial and temporal thrust profiles, although the temporal data are limited in resolution to $\sim 1 / 40 \mathrm{~s}$. The use of the PMFS technique was previously compared to and validated by a traditional inverted pendulum thrust stand in a 9-m-long 6-m-diam vacuum chamber using the P5 Hall thruster [20]. Other groups have employed similar plasma momentum flux sensors, the use of which has been attractive owing to size, cost, and configuration limitations commonly associated with thrust stands [23-32]. When integrated over an entire diameter scan, the force measurements are treated as a measure of the thrust from the VX-200 engine, and the term "thrust" will be used throughout the paper. The PMFS was located at $z=70 \mathrm{~cm}$ and scanned radially in both directions for most of the data presented in this paper.

\section{E. Retarding Potential Analyzer}

Measurements of the ion energy in the exhaust region were made with a four-grid retarding potential analyzer (RPA) [9] of a new design that was optimized for operation in a plasma environment with plasma densities up to $10^{20} \mathrm{~m}^{-3}$ and a heat flux of up to $10 \mathrm{MW} / \mathrm{m}^{2}$. The attenuator and repulsion grids were 635 and 100 wire $/ \mathrm{cm}$ stainless steel mesh, respectively, spaced $3 \mathrm{~mm}$ apart with alumina spacers. The opening apertures to the RPA consisted of $210.2 \mathrm{~mm}$ holes spaced evenly over a 1-cm-diam area of pyrolytic graphite that yielded a $1 \%$ transparency. The 21 entrance holes' length-to-diameter ratios were such that they would allow ions to enter at up to an $11 \mathrm{deg}$ half-angle. A four-grid configuration was used, with entrance attenuator, electron suppressor, ion analyzer, and secondary suppressor grids. The ion exhaust velocity was deduced from the raw data by means of a least-squares fit of a drifting Maxwellian distribution to the current-voltage data from the RPA [33-36]. The plasma potential was periodically measured near the RPA using a single Langmuir probe [9]. RPAs work by varying a repelling potential on the ion analyzer grid. Ions with a flow kinetic energy greater than the retarding electrostatic potential energy reach the collector. Since multiply ionized ions do not have the same ion cyclotron frequency, they will have a very different energy distribution and flow velocity than the singly ionized ions that are accelerated by the ICH stage of the VX-200 engine. Multiple component ion populations appear in RPA data as a stepped currentvoltage characteristic, which must be analyzed by fitting a multicomponent distribution. Previous studies of a $10 \%$ deuterium, $90 \%$ hydrogen plasma in a VASIMR device have demonstrated that a plasma with a $10 \%$ component with a mass to charge ratio differing by a factor of two can easily be resolved [37]. Based on these prior results, it is a conservative estimate that the RPA would have seen a resolvable second lower energy Maxwellian population with a detection level of 5\% of the singly ionized Maxwellian population $[37,38]$. Multiply charged ions were not detected within the limits of the RPA. The RPA was located at $z=70 \mathrm{~cm}$ and scanned radially in both directions for most of the data presented in this paper.

\section{F. Optical Spectrometer}

Data from an Ocean Optics USB4000 fiber optic spectrometer were used to look for spectral emission lines from neutral argon (ArI), singly ionized argon (ArII), doubly ionized argon (ArIII), triply ionized argon (ArIV), and trace impurities in the plume at $Z=$ $0.05 \mathrm{~m}$ and $R=0 \mathrm{~m}$. The spectrometer had a wavelength range of 200 to $1100 \mathrm{~nm}$ with a resolution of $0.3 \mathrm{~nm}$. Light input to the spectrometer was gathered by a 2 deg collimation lens looking through the diameter of the exhaust plume at a matte black plate on the far side of the plume, which was used to absorb reflected light from stray sources. The National Institute of Standards and Technology atomic spectra database was used to identify ArI, ArII, ArIII, ArIV and other spectral lines.iti

\section{Experimental Results and Discussion}

For the first time, the total thrust from the VX-200 engine has been measured at the full operating RF power level of $200 \mathrm{~kW}$. Using the PMFS, the force density within the exhaust plume of the VX-200 engine was measured as a function of the radial and axial positions. To determine the total thrust produced by the VX-200 engine, the force density over one full radius of the exhaust plume, as shown in Fig. 3a, was integrated assuming azimuthal symmetry. As the coupled RF power was increased from 28 to $200 \mathrm{~kW}$, the total force produced by the VX-200 engine was measured using the PMFS. As shown in Fig. $3 b$, the total force increased with increasing ICH coupled RF power as expected.

For the data presented in Figs. $\underline{3 a}$ and $3 \underline{b}$, the PMFS was located at $Z=0.4 \mathrm{~m}$, where $E_{\|} /\left(E_{\|} / E_{\perp}\right)=0.98$. The PMFS was $0.09 \mathrm{~m}$ in diameter, which is small compared to the total exhaust plume diameter of approximately $0.7 \mathrm{~m}$. The representative set of force density data for Fig. 3a were taken radially at 14 samples/cm from $R=0 \mathrm{~m}$ to $R=0.4 \overline{\mathrm{m}}$, and they were taken axially at one sample every $0.1 \mathrm{~m}$ from $Z=0.4 \mathrm{~m}$ to $Z=2.6 \mathrm{~m}$. The $\mathrm{VX}-200$ engine was operated with $107 \mathrm{mg} / \mathrm{s}$ of Ar propellant, a peak magnetic field strength of $20,000 \mathrm{G}$, a helicon coupled RF power level of $28 \mathrm{~kW}$; and it was operated at an ICH coupled RF power level of $90 \mathrm{~kW}$ for the data presented in Fig. 3a, and an $\mathrm{ICH}$ power level range of 0 to $172 \mathrm{~kW}$ for the data presented in Fig. $3 \mathrm{~b}$. The total measured thrust had less than a $1 \%$ difference from measurements made at various axial locations in the exhaust plume from $Z=0.4$ to $2.6 \mathrm{~m}$.

\section{A. Optimized Thruster Performance}

\section{Nozzle Divergence Angle}

The ion current density and force density were mapped over a large region of the exhaust plume: $Z=0.4$ to $2.6 \mathrm{~m}$ axially with a resolution of $0.1 \mathrm{~m}$, and $R=0$ to $\pm 0.75 \mathrm{~m}$ radially with a resolution of $0.7 \mathrm{~mm}$, with the flat faces of the ion current density probes and the PMFS always in a plane orthogonal to the VX-200 engine axis, i.e., always facing in the direction parallel to the engine axis. This mapping was performed at a total coupled RF power level of $118 \mathrm{~kW}$ and a neutral background pressure of $1 \times 10^{-3} \mathrm{~Pa}\left(1 \times 10^{-5}\right.$ torr $)$. The plasma jet data exhibited a well-defined edge in both ion current density and force density [11], which is observed in other heliconbased devices [34]. Assuming azimuthal symmetry, the conical boundary contour that surrounded $90 \%$ of the maximum value of ion current density and force density was used to find the integrated values. The angle of that boundary line relative to the VX-200 engine axis $\theta$ provided an estimate of the exhaust divergence half-angle [39]. The ion current density data yielded a divergence half-angle of $20 \pm 2 \mathrm{deg}$, while the force density data yielded a divergence halfangle of $18 \pm 2 \mathrm{deg}$. The half-angles were found by radially integrating the ion current density and force density to $90 \%$ of the total ion current and total thrust, respectively.

\footnotetext{
${ }^{\dagger \dagger}$ Data available at http://physics.nist.gov/cgi-bin/AtData/lines_form [retrieved 26 January 2011].
} 


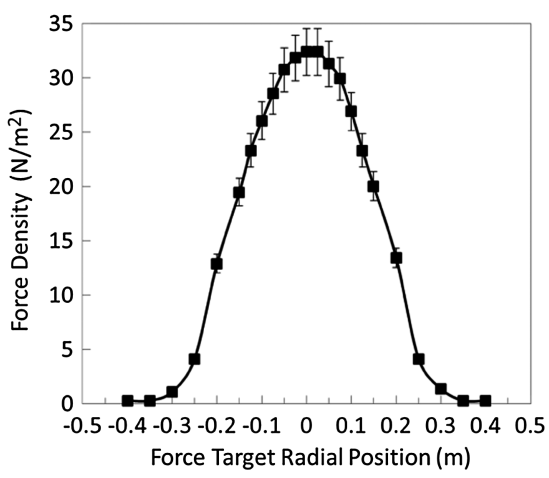

a)

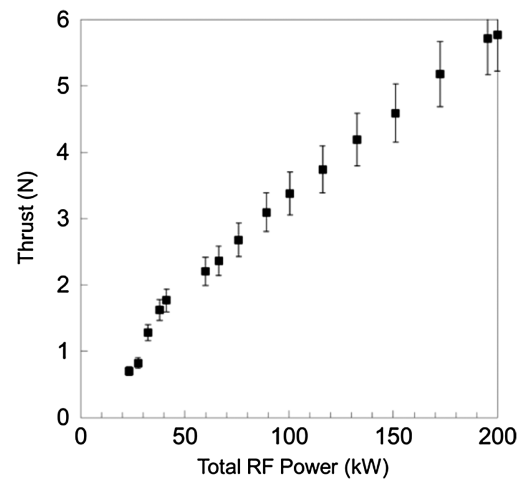

b)

Fig. 3 Representations of a) measured diameter profile of VX-200 engine force density during a $108 \mathrm{~kW}$ firing, and b) total thrust of exhaust plasma impinging on thrust target as a function of RF power coupled to an argon plasma. Measurements were taken $70 \mathrm{~cm}$ downstream from the exit plane.

The ion flux probe and the PMFS were not rotated such that the ions impacted normal to these surfaces, but they were left facing in the direction parallel to the VX-200 engine centerline and translated radially. The integrated ion current density and force density data yield a nozzle efficiency [10] $\eta_{n}$ of 97 and $98 \%$, respectively, for the plume in the region from $Z=0.4 \mathrm{~m}$ to $Z=1.6 \mathrm{~m}$. Plume divergence angle, nozzle efficiency, and plasma detachment details farther downstream than $Z=1.6 \mathrm{~m}$ are not known since the plume size exceeds the $1 \mathrm{~m}$ radial range of the translation stage. For the following system efficiency analysis, the more conservative $97 \%$ nozzle efficiency was used. This estimate was consistent with particle trajectory modeling [40] that predicted a nozzle efficiency of $90 \%$. Calculations based on a magnetohydrodynamics (MHD) theory $[40,41]$ that factored in possible drag effects owing to the plasma leaving the high magnetic strength zone yielded a nozzle efficiency of $87 \%$, although recent experimental data show that the plasma detachment from the magnetic nozzle does not follow MHD predictions $[12,42]$. Recent data with argon plasma suggest the ions separate at higher magnetic field strengths than traditional MHD fluid models of super-Alfvénic flow prediction. The electrons remain magnetized in the magnetic nozzle region and are assumed to separate to some extent from the vacuum magnetic field farther downstream near the $\beta=1$ transition. Research on plasma detachment mechanisms within the magnetic nozzle continues [43].

The total thruster efficiency $\eta_{T}$ of the VX-200 engine was determined by dividing the total RF power coupled to the plasma by the thruster jet power, where the jet power is defined as

$$
P_{\text {jet }}=\frac{T^{2}}{2 \dot{m}}
$$

where $T$ is the total thrust produced by the engine, and $\dot{m}$ is the total mass flow rate of propellant. Dividing Eq. (1) by the total RF power coupled to the plasma yields

$$
\eta_{T}=\frac{P_{\text {jet }}}{P_{\mathrm{HEL}}+P_{\mathrm{ICH}}}
$$

where $P_{\mathrm{HEL}}$ and $P_{\mathrm{ICH}}$ represent the RF power coupled to the helicon and ICH stages of VX-200 engine, respectively. Specific impulse is defined as

$$
I_{\mathrm{sp}}=\frac{T}{\dot{m} g}
$$

\section{Optimized Thrust-to-Power}

For both commercial and military satellites being transferred from one orbit to another by electric propulsion, it is usually desirable to minimize the transfer time. For this application, operating the electric thruster at its maximum thrust/power (the ratio of thrust to total RF power) minimizes the transfer time, given a fixed power level provided by a solar array. The thrust/power ratio $(T / P)$ of the VX200 prototype was optimized over a wide range of specific impulse values from 780 to $4900 \mathrm{~s}$, with a peak $T / P$ value of $51 \pm 5 \mathrm{mN} / \mathrm{kW}$ at a specific impulse of $1660 \pm 100 \mathrm{~s}$, achieved with an ICH-tohelicon power ratio of $0.7: 1$, a total RF power level of $35.4 \pm 0.5 \mathrm{~kW}$, and an Ar flow rate of $111 \pm 1 \mathrm{mg} / \mathrm{s}$; see Fig. 4 . At the high $I_{\mathrm{sp}}$ end of the thrust-to-power curve, $35 \pm 3 \mathrm{mN} / \mathrm{kW}$ was achieved with an ICH-to-helicon power ratio of 2.4, a total RF power level of $106 \pm 1 \mathrm{~kW}$, and an Ar flow rate of $101 \pm 1 \mathrm{mg} / \mathrm{s}$. These optimum thrust/power values were found at each specific impulse setting by fixing the ratio of the input $\mathrm{ICH}$ power to input helicon power and then finding a propellant flow rate that maximized the $T / P$. Each data point in Fig. 4 required hundreds of firings to find the optimum $T / P$ ratio. The average difference in performance between two different shots with the same settings was less than $1 \%$. This procedure was repeated for a variety of ICH-to-helicon power levels and for a variety of total power levels. Figure $\underline{4}$ represents the optimized values of $T / P$ for a variety of mass flow settings and ICH-to-helicon power levels and total power levels. However, higher total power levels generally resulted in higher $T / P$ values since the VX-200 prototype was designed for highest efficiency at a total power level of $200 \mathrm{~kW}$. The resultant non-monotonic shape to the data in Fig. 4 is a complex balance between the changing ionization cost as a function of helicon-to-ICH power, propellant utilization, RF wave absorption physics, and the fact that the total power for the thruster system has a maximum of $200 \mathrm{~kW}$. Generally, at the high $I_{\mathrm{sp}}$ end of the curve, more power is invested in ion kinetic energy instead of ionizing a larger number of particles, resulting in a decreasing $T / P$ trend with increasing $I_{\mathrm{sp}}$. At very low $I_{\mathrm{sp}}$ values, the ionization process is less efficient and a small increase in $I_{\mathrm{sp}}$ results in increased $T / P$ values. Similarly shaped curves are observed with Hall effect thrusters and ion thrusters at a fixed total power.

The data in Fig. 4 represent the optimized $T / P$ values for the VX200 prototype in its present configuration with a highly optimized

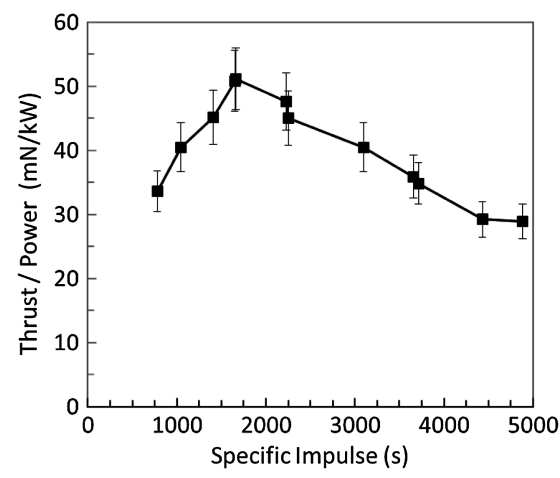

Fig. 4 Thrust-to-power ratio as a function of the specific impulse for argon propellant. A maximum in thrust-to-power occurs in the VX200 engine for a specific impulse value of $1660 \mathrm{~s}$. 


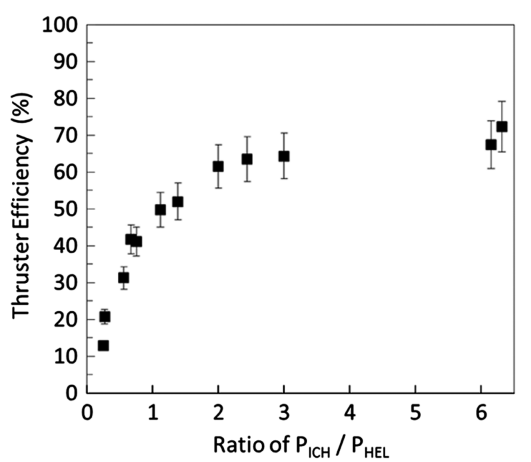

a)

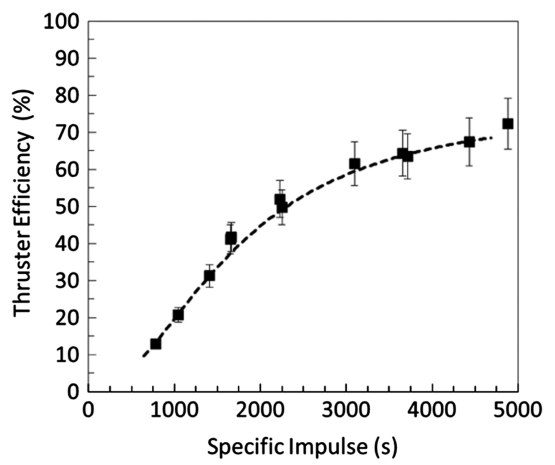

b)

Fig. 5 Representations of a) thruster efficiency of the VX-200 engine as a function of the ICH RF power to helicon RF power ratio over a range from 15 to $200 \mathrm{~kW}$ coupled RF power and 80 to $110 \mathrm{mg} / \mathrm{s} \mathrm{Ar}$, and b) as a function of specific impulse. A least-squares fit of the data to a semiempirical model is also superimposed (dashed line).

ICH coupler design. The data were taken for argon propellant only, and Sec. III.C points to a semiempirical model that was fit to the argon data and then extrapolated for krypton operation. As a point of reference to the data presented in Fig. 4, the highest-power Hall effect thruster that has been operated in spaceflight $(5.5 \mathrm{~kW})$ has a throttle table that includes $T / P$ ratios from 40 to $60 \mathrm{mN} / \mathrm{kW}$ over a specific impulse range from 1000 to $2600 \mathrm{~s}$ [44]

\section{Optimized Thruster Efficiency}

Figure 5a shows the total thruster efficiency as a function of the ratio of $P_{\mathrm{ICH}} / P_{\mathrm{HEL}}$, and Fig. $5 \mathrm{~b}$ shows the specific impulse, where the specific impulse was calculated using Eq. (3) with measured values of thrust and propellant flow rate; the total thruster efficiency was calculated using Eq. (2). For the data presented in Fig. 5, the VX200 engine used a propellant flow rate from 80 to $11 \overline{0} \mathrm{mg} / \mathrm{s}$, a coupled helicon RF power level from 15 to $30 \mathrm{~kW}$, and a coupled ICH RF power level from 0 to $172 \mathrm{~kW}$. The maximum thrust obtained in this parameter scan was $5.8 \pm 0.4 \mathrm{~N}$, at an $I_{\mathrm{sp}}$ of $4900 \pm 300 \mathrm{~s}$, with a $72 \pm 6 \%$ thruster efficiency. Previous RPA data were used to corroborate the specific impulse inferred from the PMFS force measurements. RPA measurements were taken at power levels up to $136 \mathrm{~kW}$ and matched the PMFS measurements with an error of less than $3 \%$. At RF power levels up to $136 \mathrm{~kW}$, the RPA was used to verify the PMFS results and reported a mean ion flow velocity of $32.8 \mathrm{~km} / \mathrm{s}$ with an ion temperature of $\sim 50 \mathrm{eV}$ in the frame of reference moving with the beam. RPA measurements were not possible at power levels higher than $136 \mathrm{~kW}$, as the power density of the plasma exhaust led to RPA grid degradation. However, RPA measurements showed, at most, a 3\% error compared to the PMFS at a total RF power level of $136 \mathrm{~kW}$. The experimental data in Figs. 5a and $5 \mathrm{~b}$ were the same, but they are presented in a different format in each graph.

Any change to the thruster efficiency was due largely to the increasing component of ICH coupled RF power. The limiting factor in the maximum ICH coupled RF power to the VX-200 engine was a vacuum pressure limit within the vacuum chamber, where greater RF circuit voltages produced glow or arc discharges that prompted the VX-200 engine solid-state RF generators to shut down. This is reflected in the gap in the data for Fig. 5a, as total runtime was limited and only a smaller number of shots were performed. The total thruster efficiency in Fig. 5 increases as a function of coupled ICH RF power and $I_{\mathrm{sp}}$, indicating that the process of $\mathrm{ICH}$ wave coupling into the plasma kinetic energy has not saturated, i.e., $\eta_{\mathrm{IC}}$ does not decrease with increasing RF power or increasing $I_{\mathrm{sp}}[10]$.

Measurements of the ionization cost, defined as the ratio of the coupled RF power to the total ion current that is extracted from the system in the exhaust section, were taken during helicon-only operation as a function of both coupled RF power and argon propellant flow rate: from 15 to $35 \mathrm{~kW}$ and 50 to $160 \mathrm{mg} / \mathrm{s}$, respectively, for argon; and 100 to $250 \mathrm{mg} / \mathrm{s}$ for krypton. The lowest ionization cost measurement of $80 \pm 9 \mathrm{eV}$ for argon and $70 \pm 9 \mathrm{eV}$ for krypton occurred with VX-200 engine settings of $33 \mathrm{~kW}$ coupled
RF power and $160 \mathrm{mg} / \mathrm{s}$ and $18 \mathrm{~kW}$ coupled RF power and $250 \mathrm{mg} / \mathrm{s}$, respectively. The ionization cost term $E_{i}$ appears in Eq. (4). Although a small fraction of ICH power may be absorbed by electrons, for the purposes of the semiempirical model in Eq. (4), it is assumed that the ICH process does not affect $E_{i}$.

A least-squares fit to the data is used with a semiempirical model of the thruster efficiency $[16,28]$ for the VX-200 engine similar to Eq. (4), where the ICH coupling efficiency $\eta_{I C}$ is the only free parameter, such that

$$
\eta_{T}=\frac{(1 / 2) m_{i} g^{2} I_{\mathrm{sp}}^{2}}{e E_{i}+e E_{1}\left(1-1 / \eta_{B}\right)+\left\{\left[(1 / 2) m_{i} g^{2} I_{\mathrm{sp}}^{2}\right] / \eta_{\mathrm{IC}} \eta_{n}\right\}}
$$

where $m_{i}$ is the atomic mass, $g$ is the gravitational acceleration, $I_{\mathrm{sp}}$ is the specific impulse, $e$ is the electron charge, $E_{i}$ is the ionization cost of the propellant, $E_{1}$ is the first-stage (helicon) RF power coupled to the plasma that is converted into directed ion kinetic energy through ambipolar acceleration, $\eta_{\mathrm{IC}}$ is the ion cyclotron heating efficiency for power coupled to the ions, and $\eta_{n}$ is the nozzle efficiency. The ionization cost of the propellant for $29 \mathrm{~kW}$ helicon power and $107 \mathrm{mg} / \mathrm{s} \mathrm{Ar}$ was $E_{i}=105 \pm 9 \mathrm{eV} /$ ion-extracted, the kinetic energy of ions leaving the first stage was $E_{1}=22 \pm 2 \mathrm{eV}$, and the nozzle efficiency was $\eta_{n}=97 \%$. The only free parameter remaining from Eq. (4) is the ICH coupling efficiency $\eta_{\mathrm{IC}}$, which was fit to the data using a least-squares algorithm, and it was found to be $85 \pm 7 \%$. It should be noted that $\eta_{\text {IC }}$ also includes the efficiency loss due to the ion energy spread in the exhaust, i.e., the frozen flow losses due to the finite ion temperature. The ionization energy for argon and krypton are 15.8 and $14.0 \mathrm{eV}$, respectively, although a practical lower limit is usually taken to be twice the ionization energy, owing to scattering collisions. Decreasing $E_{i}$ or increasing $E_{1}$ shifts the semiempirical model curve to the left, and increasing $\eta_{\mathrm{IC}}$ or $\eta_{n}$ shifts the curve upward. The VX-200 engine helicon coupler and ICH coupler were designed to produce a thruster efficiency of $60 \%$ at $5000 \mathrm{~s}$ using $200 \mathrm{~kW}$ dc input power (equivalent to $186 \mathrm{~kW}$ RF power). This compares to the measured performance of the VX-200 using the full $200 \mathrm{~kW}$ of RF power, which achieved a $72 \pm 6 \%$ thruster efficiency at a specific impulse of $4900 \pm 300 \mathrm{~s}$, significantly exceeding the performance and design specifications.

\section{Doubly and Triply Ionized Species}

Secondary $\left(\mathrm{Ar}^{2+}\right)$ or tertiary $\left(\mathrm{Ar}^{3+}\right)$ ionization states were not detected to within $1 \%$ of the $\mathrm{Ar}^{+}$population based on spectrometer measurements at a location of $0.3 \mathrm{~m}$ downstream of the VX-200 engine exit plane. In addition, $\mathrm{Ar}^{2+}$ and $\mathrm{Ar}^{3+}$ ions are not detected to within 5\% of the $\mathrm{Ar}^{+}$population based on RPA data at a location of $Z=0.4 \mathrm{~m}$. This low fraction of $\mathrm{Ar}^{2+}$ and $\mathrm{Ar}^{3+}$ is somewhat unique to magnetoplasma thrusters as the ion acceleration mechanism is separated from the plasma generation mechanism. 


\section{B. Helicon Plasma Source Performance with Argon and Krypton}

Experiments designed to measure the performance of the helicon plasma source stage were performed using argon propellant over an applied RF power range from 10 to $33 \mathrm{~kW}$ and a propellant flow rate range from 50 to $160 \mathrm{mg} / \mathrm{s}$. These experiments were also performed with krypton propellant for the same applied RF power range and a similar particle flow rate, although a different mass flow rate range of 100 to $250 \mathrm{mg} / \mathrm{s}$. The efficiency of the helicon plasma source was characterized in terms of ionization cost of the propellant [Eq. (4)], as well as the ionization fraction (Fig. 6). Similar to many Hall and ion thruster ionization cost characterizations, a conservative approach is taken and the ion current from the helicon plasma source is measured at the exit plane of the engine instead of within the core itself. This results in an effective ionization cost of extracted ions from the thruster. Precaution was also taken such that the ion flux probes were biased $3 T_{e}$ more negative than the plasma floating potential, ensuring that extra ion current was not collected as a result of ion impact ionization with the probe tip and excess electron reflection at the probe sheath. The ionization cost is expressed as

$$
E_{i}=\frac{P_{\mathrm{HEL}}}{I_{\mathrm{ion}}}-E_{1}
$$

where $P_{\text {HEL }}$ is the RF power coupled to the helicon source, $I_{\text {ion }}$ is the total ion current from the engine, and $E_{1}$ is the first-stage (helicon) RF power coupled to the plasma that is converted into directed ion kinetic energy through ambipolar acceleration.

The helicon performance data indicate that a larger operational envelope, in terms of RF power and propellant flow rate, is possible when using krypton propellant compared to argon propellant. This is somewhat expected since the ionization energy for krypton $(14.0 \mathrm{eV})$ is lower than it is for argon $(15.8 \mathrm{eV})$, in addition to the fact that the
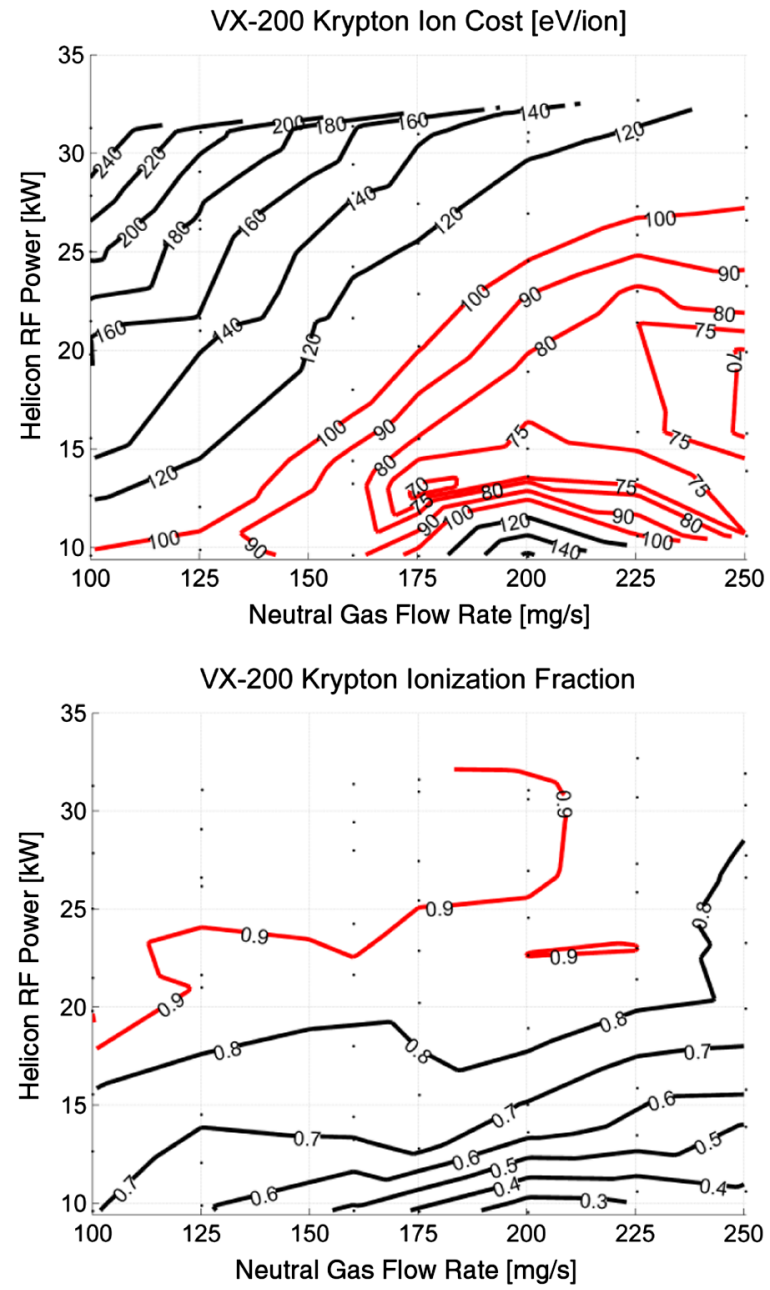

thermal sound speed of neutral krypton atoms is $30 \%$ slower than it is for argon, which increases the neutral krypton residence time within the helicon source.

Metastable states play an important role in the ionization process of argon gas, which in some cases can act to decrease the effective ionization cost when compared to atoms that do not have many metastable states $[45,46]$. Not as much work has been performed with krypton metastable states, although it is thought that this also plays an important role in the ionization process of krypton. The nonblack lines on the ion cost graphs for argon (right) and krypton (left) in Fig. 6 show contour regions where the ion cost is less than $100 \mathrm{eV} /$ ion, which is a desired design parameter of the plasma source for use within the VX-200. Note that the regions with ion costs below $100 \mathrm{eV} /$ ion are much larger for krypton than with argon, indicating that for at least the current design of the VX-200, krypton provides a wider helicon plasma source throttling range. Regions as low as $80 \mathrm{eV} /$ ion are possible with argon propellant and as low as $70 \mathrm{eV} /$ ion with krypton propellant within the helicon plasma source of the VX-200. Some of the regions within Fig. 6 are non-monotonic, and the authors attribute the complex contours to a balance between increased electron temperature, which leads to enhanced ionization efficiency, and particle and radiation losses. A description of this process has been analyzed analytically in the past [47]. Figure $\underline{6}$ also shows graphs of the ion fraction for both argon and krypton propellants, where both regions of ion fraction greater than $90 \%$ are similar.

The lower ionization cost for krypton, compared to argon, is positive for not only improving the helicon stage of the VX-200 but also being able to achieve higher $T / P$ ratios during full $\mathrm{ICH}$ operations of the VX-200 prototype due solely to the increased thruster efficiency at lower specific impulse settings. This helicon performance work with krypton lays the groundwork for possible
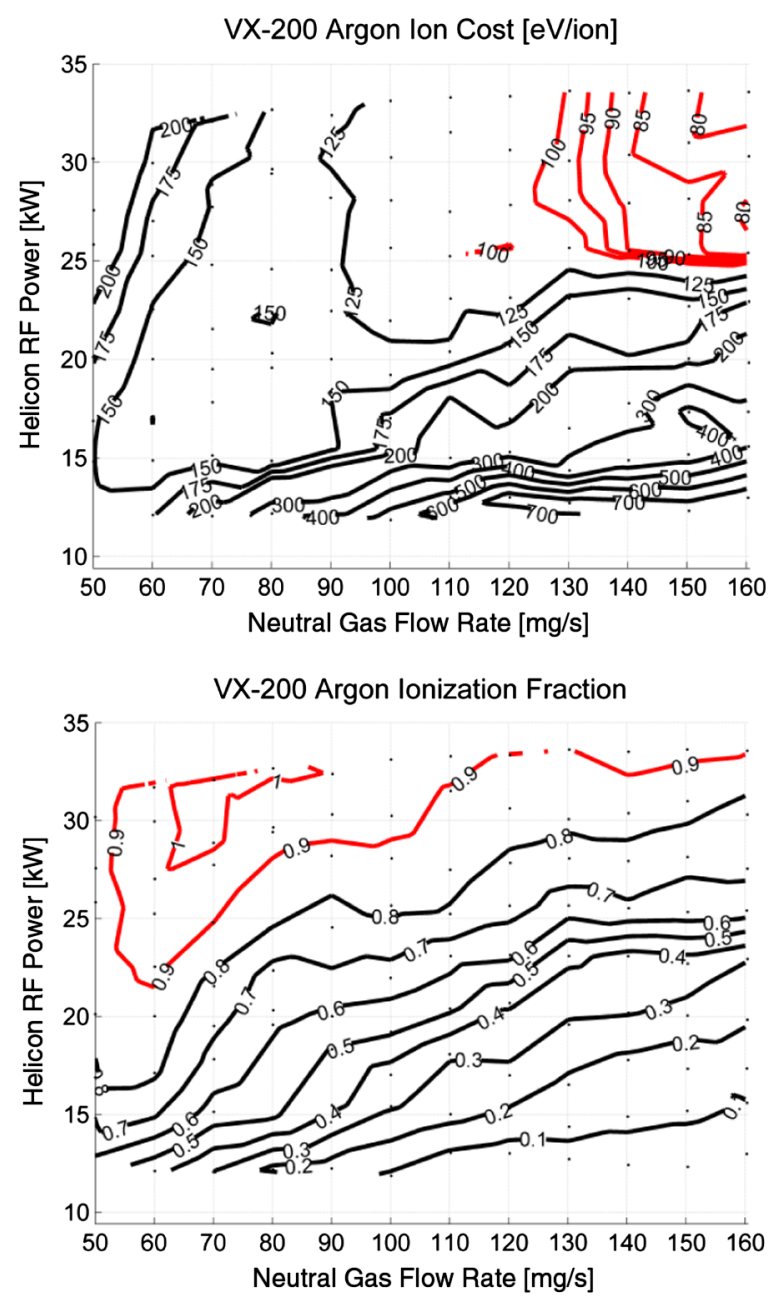

Fig. 6 Ion cost (upper) and ionization fraction (lower) of the VX-200 engine exhaust plume for argon (right) and krypton (left) propellants. 


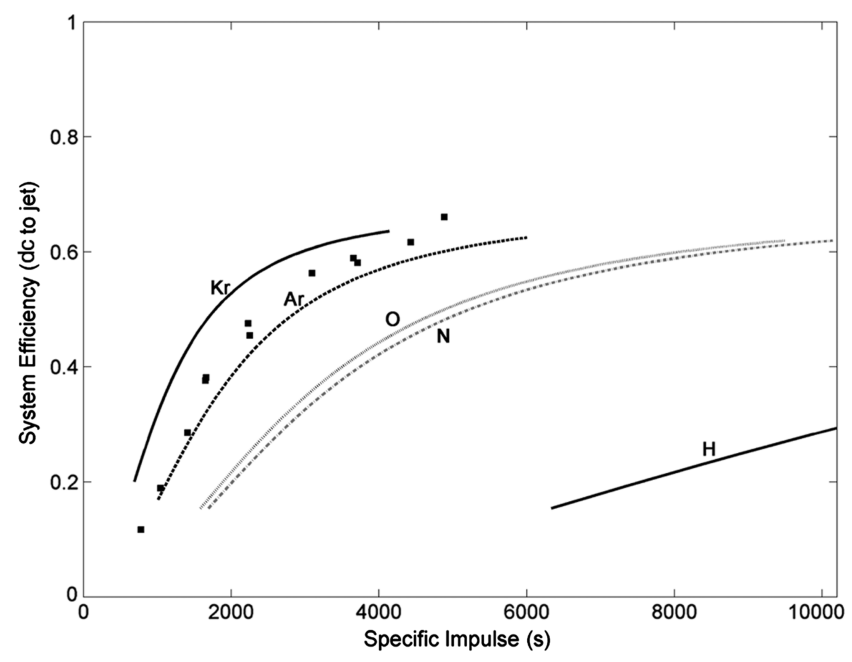

Fig. 7 Analytic model [10] of system efficiency of the VX-200 engine as a function of the specific impulse for various propellants and measured system efficiency of the VX-200 prototype for argon (squares).

future performance measurements using full-power ICH with the existing magnet of the VX-200 and an altered ICH generator frequency compared to the settings used for argon. It remains to be seen if ICH coupling efficiency in krypton plasma will be as high as that with argon plasma, which is as high as $85 \%$. One complication with krypton operations is that it has multiple stable isotopes that would tend to change the resonance location within the ICH stage. However, in simulations, this resonance location only changes by a distance on the order of millimeters.

\section{Semiempirical Model of Krypton ICH Performance}

One of the driving factors for electric propulsion thruster design is the cost of delivering spacecraft or payloads to a desired orbital destination. To minimize cost and shorten trip time, a VX-200-like thruster designed for operations in and around low Earth orbit (LEO) out to geostationary Earth orbit (GEO) should typically have specific impulse values of 1500 to $2500 \mathrm{~s}$ [4,48]. With a fixed power system (i.e., solar panels), lower specific impulse values generally result in higher $T / P$ ratios, which reduce trip time.

For the VX-200 to operate efficiently, defined here as a thruster efficiency exceeding $60 \%$ and a system efficiency exceeding $50 \%$, in a specific impulse range of 1500 to $2500 \mathrm{~s}$, a propellant with an atomic mass larger than 40 atomic mass units (amu) (Ar) should be used. For the VX-200, krypton propellant is attractive since it has an average atomic mass of 84 amu and a lower ionization energy compared to argon. Figure 7 shows modeled system efficiencies for the VX-200 operating with different propellant choices, including krypton, argon, oxygen, nitrogen, and hydrogen for a specific impulse range from 0 to $10,000 \mathrm{~s}$. Note that the hydrogen system efficiency does in fact exceed $60 \%$ but at a specific impulse of $30,000 \mathrm{~s}$. Figure 7 also shows measured VX-200 system efficiency values (including superconducting magnet power supplies and $15 \mathrm{~kW}$ laboratory cryocoolers) as a function of the measured specific impulse, up to a dc power level of $212 \mathrm{~kW}$. The various propellant curves in Fig. 7 show ion energies from $20 \mathrm{eV}$ up to $700 \mathrm{eV}$, which is representative of the full throttling range of the VX-200. This throttling range goes from helicon-only operation of $30 \mathrm{~kW}$ (ambipolar ion acceleration of $\sim 20 \mathrm{eV}$ ) up to an anticipated system power level of $300 \mathrm{~kW}$ (30 kW helicon RF power, $270 \mathrm{~kW} \mathrm{ICH} \mathrm{RF}$ power). An assumption is made that the helicon power level is fixed at $30 \mathrm{~kW}$ for all of the analytical curves in Fig. 7.

For near-term applications in LEO, a specific impulse in the range of 1500 to $2500 \mathrm{~s}$ is more desirable since this optimizes cost and trip time of most orbital transfer missions. Krypton provides an interesting option for VX-200 operation in the LEO, medium-Earthorbit, and GEO environments owing to the fact that a higher thruster efficiency is possible at a lower specific impulse compared to operation with argon propellant. Analytical models, based on Eq. (4), predict that a system efficiency exceeding $50 \%$ is possible for specific impulse values exceeding $2000 \mathrm{~s}$. Because the ion cyclotron heating process is a resonant process, the ICH RF driving frequency and/or magnetic field strength needs to be modified for each propellant.

\section{Conclusions}

The thruster efficiency and total thrust of the VASIMR VX-200 laboratory prototype have been measured at an input power level of $200 \mathrm{~kW}$ with argon propellant operating inside a vacuum chamber with sufficient volume and pumping to achieve a charge-exchange mean free path in excess of the chamber length. Using an ion flux probe array and a plasma momentum flux sensor, the exhaust of the VX-200 engine was characterized as a function of the total RF power, propellant flow rate, and the radial and axial positions within the exhaust plume. A thruster efficiency of $72 \%$ was determined using the thrust measurements and propellant flow rate with a specific impulse of $4880 \mathrm{~s}$ when operated at a total coupled RF power of $200 \mathrm{~kW}$. The ionization cost of argon propellant was determined to be $80 \mathrm{eV}$ /ion for optimized values of RF power and propellant flow rate, and $70 \mathrm{eV} /$ ion for krypton propellant. A semiempirical fit to the full-power performance data indicated an ICH efficiency of $85 \%$ at $200 \mathrm{~kW}$ total coupled RF power (212 kW total dc input power). A high thrust-to-power operating mode was characterized over a wide parameter space with a maximum thrust-to-power ratio of $51 \mathrm{mN} / \mathrm{kW}$ at a specific impulse of $1660 \mathrm{~s}$ for a ratio of ICH RF power to helicon RF power of $0.7: 1$. The throttling optimization showed a thruster efficiency curve that exceeded $50 \%$ for a specific impulse of $2000 \mathrm{~s}$ and higher. This work paves the way for further VX-200 development and ICH operation with krypton propellant, which promises to yield an improved thrust-to-power ratio and a higher thruster efficiency at lower specific impulse values, which is more closely optimized for spaceflight applications within the sphere of influence of the Earth.

\section{Acknowledgment}

All of the testing and research funding was provided by, and conducted at, the Ad Astra Rocket Company in Webster, Texas.

\section{References}

[1] Frisbee, R., "SP-100 Nuclear Electric Propulsion for Mars Cargo Missions," 29th AIAA/SAE/ASME/ASEE Joint Propulsion Conference, AIAA Paper 1993-2092, June 1993.

[2] Frisbee, R., "Electric Propulsion Options for Mars Cargo Missions," 32nd AIAA/ASME/SAE/ASEE Joint Propulsion Conference and Exhibit, AIAA Paper 1996-3173, July 1996.

[3] Sankaran, K., Cassady, L., Kodys, A., and Choueiri, E., "A Survey of Propulsion Options for Cargo and Piloted Missions to Mars," Astrodynamics Space Missions and Chaos, edited by Belbruno, E., Folta, D., and Gurfil, P., Vol. 1017, Annals of the New York Academy of Sciences, New York, 2004, pp. 450-567.

[4] Ilin, A., Cassady, L., Glover, T., Carter, M., and Chang Díaz, F., "A Survey of Missions Using VASIMR for Flexible Space Exploration," NASA Johnson Space Center TR-JSC-65825, April 2010.

[5] Boswell, R. W., and Chen, F. F., "Helicons: The Early Years," IEEE Transactions on Plasma Science, Vol. 25, Dec. 1997, pp. 1229-1244. doi:10.1109/27.650898

[6] Chen, F. F., and Boswell, R. W., "Helicons: The Past Decade," IEEE Transactions on Plasma Science, Vol. 25, Dec. 1997, pp. 1245-1257. doi: $10.1109 / 27.650899$

[7] Northrop, T.G., "The Adiabatic Motion of Charged Particles," American Journal of Physics, Vol. 32, No. 10, 1964, pp. 807-807. doi:10.1119/1.1969867

[8] Roederer, J. G., "Dynamics of Geomagnetically Trapped Radiation," Physics and Chemistry in Space, Springer, Berlin, 1970, pp. 7-19.

[9] Bering, E. A., III, Chang Díaz, F. R., Squire, J. P., Glover, T. W., Carter, M. D., McCaskill, G. E., Longmier, B. W., Brukardt, M. S., Chancery, W. J., and Jacobson, V. T., "Observations of Single-Pass Ion Cyclotron Heating in a Trans-Sonic Flowing Plasma," Physics of Plasmas, Vol. 17, No. 4, 2010, p. 043509. doi: $10.1063 / 1.3389205$

[10] Longmier, B., Cassady, L., Ballenger, M., Carter, M., Chang-Díaz, F., Glover, T., Ilin, A., McCaskill, G., Olsen, C., Squire, J., and Bering, E., 
"VX-200 Magnetoplasma Thruster Performance Results Exceeding Fifty-Percent Thruster Efficiency," Journal of Propulsion and Power, Vol. 27, No. 4, 2011, pp. 915-920. doi:10.2514/1.B34085

[11] Terasaka, K., Yoshimura, S., Ogiwara, K., Aramaki, M., and Tanaka, M., "Experimental Studies on Ion Acceleration and Stream Line Detachment in a Diverging Magnetic Field," Physics of Plasmas, Vol. 17, No. 7, 2010, p. 072106 doi:10.1063/1.3457139

[12] Olsen, C., "Experimental Characterization of Plasma Detachment from Magnetic Nozzles," Ph.D. Dissertation, Rice Univ., Houston, TX, May 2013.

[13] Gesto, F. N., Kim, J. H., and Chang, H. Y., "Electrical Characteristics of Helicon Wave Plasmas," Journal of Propulsion and Power, Vol. 22, No. 1, 2006, pp. 24-30. doi: $10.2514 / 1.13914$

[14] Deline, C.A., Bengston, R. D., Breizman, B. N., Tushentsov, M. R., Jones, J. E., Chavers, D. G., Dobson, C. C., and Schuettpelz, B. M., "Plume Detachment from a Magnetic Nozzle," Physics of Plasmas, Vol. 16, No. 3, 2009, Paper 033502 doi:10.1063/1.3080206

[15] Yun, S. M., Kim, J. H., and Chang, H. Y., "Electrical Characterization of Helicon Wave Plasmas," IEEE Transactions on Plasma Science, Vol. 26, No. 2, April 1998, pp. 159-166.

[16] Longmier, B., Bering, E., Carter, M., Cassady, L., Chancery, W., Chang Díaz, F., Glover, T., Hershkowitz, N., Ilin, A., McCaskill, G., Olsen, C., and Squire, J., "Ambipolar Ion Acceleration in an Expanding Magnetic Nozzle," Plasma Sources Science and Technology, Vol. 20, No. 1, 2011, Paper 015007. doi:10.1088/0963-0252/20/1/015007

[17] Longmier, B. W., Bering, E. A., Squire, J. P., Glover, T. W., Chang Diaz, F. R., and Brukardt, M., "Exhaust Plume Measurements of the VASIMR VX-200," 50th Annual Meeting of the Division of Plasma Physics, Vol. 53, American Physical Society Paper BAPS.2008.DPP.U05.7, Dallas, TX, Nov. 2008.

[18] West, M., Charles, C., and Boswell, R., "Operating Radio Frequency Antennas Immersed in Vacuum: Implications for Ground-Testing Plasma Thrusters," Journal of Propulsion and Power, Vol. 26, No. 4, 2010, pp. 892-896.

doi: $10.2514 / 1.4938$

[19] Olsen, C., "Ion Flux Maps and Helicon Source Efficiency in the VASIMR VX-100 Experiment Using a Moving Langmuir Probe Array," M.S. Thesis, Rice Univ., Houston, TX, Feb. 2009.

[20] Longmier, B., Reid, B., Gallimore, A., Chang Díaz, F., Squire, J., Glover, T., Chavers, G., and Bering, E., "Validating a Plasma Momentum Flux Sensor to an Inverted Pendulum Thrust Stand," Journal of Propulsion and Power, Vol. 25, No. 3, 2009, pp. 746-752. doi:10.2514/1.35706

[21] Chavers, G., and Chang-Díaz, F., Momentum Flux Measuring Instrument for Neutral, and Charged Particle Flows, Review of Scientific Instruments, Vol. 73, No. 3500, 2002, pp. 3500-3507. doi:10.1063/1.1505107

[22] Chavers, G., Chang-Diaz, F., Irvine, C., and Squire, J., "Momentum And Heat Flux Measurements Using an Impact Target in Flowing Plasma," Journal of Propulsion and Power, Vol. 22, No. 4, 2006, pp. 637-644.

[23] Yanagi, R., and Kimura, I., "New Type of Target for the Measurement of Impulse Bits of Pulsed Plasma Thrusters," Journal of Spacecraft and Rockets, Vol. 19, No. 3, 1982, pp. 246-249. doi: $10.2514 / 3.62245$

[24] Grun, J., and Ripin, B., "Ballistic Pendula for Measuring the Momentum of a Laser- Produced Plasma," Review of Scientific Instruments, Vol. 53, No. 12,1982 , pp. 1878-1881. doi:10.1063/1.1136897

[25] Cohen, S., Zonca, F., Timberlake, J., Bennett, T., Cuthbertson, J., Langer, W., and Motley, R., "An Instrument for Measuring the Momentum Flux from Atomic and Charged Particle Jets," Review of Scientific Instruments, Vol. 61, No. 11, 1990, pp. 3586-3591. doi:10.1063/1.1141575

[26] Takao, Y., Eriguchi, K., and Ono, K., "A Miniature Electrothermal Thruster Using Microwave-Excited Microplasmas: Thrust Measurement and its Comparison with Numerical Analysis," Journal of Applied Physics, Vol. 101, No. 12, 2007, Paper 123307. doi:10.1063/1.2749336

[27] Lunt, T., Silva, C., Fernandes, H., Hidalgo, C., Pedrosa, M. A., Duarte, P., Figueiredo, H., and Pereira, T., "Edge Plasma Pressure Measurements Using a Mechanical Force Sensor on the Tokamak ISTTOK," Plasma Physics and Controlled Fusion, Vol. 49, No. 11,
2007, pp. 1783-1790.

doi:10.1088/0741-3335/49/11/003

[28] Böhrk, H., and Auweter-Kurtz, M., "Thrust Measurement of the Hybrid Electric Thruster TIHTUS by a Baffle Plate," Journal of Propulsion and Power, Vol. 25, No. 3, 2009, pp. 729-736.

doi: $10.2514 / 1.34324$

[29] West, M., Charles, C., and Boswell, R., "A High Sensitivity Momentum Flux Measuring Instrument for Plasma Thruster Exhausts and Diffusive Plasmas," Review of Scientific Instruments, Vol. 80, No. 1, 2009, Paper 053509 . doi: $10.1063 / 1.3142477$

[30] Makrinich, G., and Fruchtman, A., "Experimental Study of a Radial Plasma Source," Physics of Plasmas, Vol. 16, No. 4, 2009, Paper 043507. doi: $10.1063 / 1.3119688$

[31] Ling, J., West, M., Lafleur, T., Charles, C., and Boswell, R., "Thrust Measurements in a Low-Magnetic Field High-Density Mode in the Helicon Double Layer Thruster," Journal of Physics D: Applied Physics, Vol. 43, No. 30, 2010, Paper 305203. doi: $10.1088 / 0022-3727 / 43 / 30 / 305203$

[32] Chen, X., "The Impact Force Acting on a Flat Plate Exposed Normally to a Rarefied Plasma Plume Issuing from an Annular or Circular Nozzle," Journal of Physics D: Applied Physics, Vol. 43, No. 31, 2010, Paper 315205

[33] Whipple, E. C., "The Ion Trap-Results in 'Exploration of the Upper Atmosphere with the Help of the Third Soviet Sputnik'," Proceedings of the IRE, Vol. 47, No. 2023, 1959, pp. 2011-2025.

[34] Parker, L. W., and Whipple, E. C., "Theory of Spacecraft Sheath Structure, Potential, and Velocity Effects on Ion Measurements by Traps and Mass Spectrometers," Journal of Geophysical Research, Vol. 75, No. 4720, 1970, pp. 4720-4733. doi:10.1029/JA075i025p04720

[35] Minami, S., and Takeya, Y., "Ion Temperature Determination in the Ionosphere by Retarding Potential Analyzer Aboard Sounding Rocket," Journal of Geophysical Research, Vol. 87, No. 713, 1982, pp. 713-730. doi:10.1029/JA087iA02p00713

[36] Hutchinson, I. H., Principles of Plasma Diagnostics, Cambridge Univ. Press, Cambridge, England, U.K., 1987, p. 155.

[37] Bering, E.A., III, Chang Díaz, F. R., and Squire, J. P., "The Uses of RF Waves in Space Propulsion Systems," Radio Science Bulletin, Vol. 310, No. 92, 2004, pp. 92-106.

[38] Cox, W., Charles, C., Boswell, R., and Hawkins, R., "Spatial retarding Field Energy Analyzer Measurements Downstream of a Helicon Double Layer Plasma," Applied Physics Letters, Vol. 93, No. 7, 2008, Paper 071505. doi: $10.1063 / 1.2965866$

[39] Sutton, R., and Biblarz, O., Rocket Propulsion Elements, 7th ed., Wiley, 2001, p. 70.

[40] Ilin, A., Chang Díaz, F., Squire, J., Tarditi, A., Breizman, B., and Carter, M., "Simulations of Plasma Detachment in VASIMR," 40th AIAA Aerospace Sciences Meeting and Exhibit, AIAA Paper 2002-0346, Jan. 2002

[41] Arefiev, A., and Breizman, B., "Magnetohydrodynamic Scenario of Plasma Detachment in a Magnetic Nozzle," Physics of Plasmas, Vol. 12, No. 4, 2005, pp. 043504-043510. doi:10.1063/1.1875632

[42] Squire, J. P., Olsen, C. S., Chang Díaz, F. R., Cassady, L. D., Longmier, B. W., Ballenger, M. G., Carter, M. D., Glover, T. W., McCaskill, G. E., and Bering, E. A., III, "VASIMR VX-200 Operation at $200 \mathrm{~kW}$ and Plume Measurements: Future Plans and an ISS EP Test Platform," 32nd International Electric Propulsion Conference, IEPC-2011-154, Electric Rocket Propulsion Society, Wiesbaden, Germany, Sept. 2011.

[43] Olsen, C. S., Squire, J. P., Longmier, B. W., Ballenger, M. G., Cassady, L. D., Carter, M. D., Cloutier, P., Ilin, A., Bering, E. A., and Giambusso, M., "Experimental Determination of Plasma Detachment from the Diverging Magnetic Nozzle of the VASIMR VX-200 Electric Thruster," 53rd Annual Meeting of the APS Division of Plasma Physics, Vol. 56, American Physical Society Paper BAPS.2011.DPP.PP9.163, Salt Lake City, UT, Nov. 2011

[44] Hofer, R. R., "High-Specific Impulse Operation of the BPT-4000 Hall Thruster for NASA Science Missions," 46th AIAA/ASME/SAE/ASEE Joint Propulsion Conference and Exhibit, AIAA Paper 2010-6623, July 2010.

[45] Phelps, A. V., and Molnar, J. P., "Lifetimes of Metastable States of Noble Gases," Physics Reviews, Vol. 89, No. 6, 1953, pp. 1202-1208.

[46] Velazco, J. E., Kolts, J. H., and Setser, D. W., "Rate Constants and Quenching Mechanisms for the Metastable States of Argon, Krypton, 
and Xenon," Journal of Chemical Physics, Vol. 69, No. 4357, 1978, pp. 4357-4373.

[47] Fruchtman, A., "Neutral Depletion in a Collisionless Plasma," IEEE Transactions on Plasma Science, Vol. 36, No. 403, 2008, pp. 403-413.

[48] Chang Díaz, F. R., Carter, M. D., Glover, T. W., Ilin, A. V., Olsen, C. S . Squire, J. P., Litchford, R. J., Harada, N., and Koontz, S. L., "Fast and Robust Human Missions to Mars with Advanced Nuclear Electric Power and VASIMR ${ }^{\circledR}$ Propulsion," Proceedings of Nuclear and Emerging Technologies for Space 2013, American Nuclear Society Paper 6777, La Grange Park, IL, Feb. 2013.

L. King Associate Editor 